\title{
ILMU RASM QURAN
}

\author{
Mira Shodiqoh \\ STIT Makhdum Ibrahim Tuban \\ email : mirashodiqoh@stitmatuban.ac.id
}

\begin{abstract}
The science of rasm of the Al-Qur'an is the study of the writing of the mushaf of the AlQur'an which is carried out in a special way, both in the writing of the pronunciations and the forms of letters used. Writing of the Al-Qur'an during the time of the Prophet Muhammad. Performed by his friends both in writing and in order with the aim to unite the Muslims in one type of Manuscripts by uniforming the reading and unifying the orderly arrangement of the verses. Thus there is no difference in understanding between the Manuscripts with other Manuscripts.
\end{abstract}

Kata Kunci: science Rasm of Al-Qur'an

\section{PENDAHULUAN}

Rasmul Al-Qur'an merupakan salah satu bagian disiplin ilmu Al-Qur'an yang mana di dalamnya mempelajari tentang penulisan Mushaf Al-Qur'an yang dilakukan dengan cara khusus, baik dalam penulisan lafal-lafalnya maupun bentuk-bentuk huruf yang digunakan. Rasmul Al-Qur'an dikenal juga dengan nama Rasm Utsmani.

Tulisan Al-Quran 'Utsmani adalah tulisan yang dinisbatkan kepada Sayyidina Utsman Ra. (Khalifah ke III). Istilah ini muncul setelah rampungnya penyalinan Al-Quran yang dilakukan oleh tim yang dibentuk oleh Ustman pada tahun $25 \mathrm{H}$., oleh para ulama. Cara penulisan ini biasanya di istilahkan dengan 'Rasmul 'Utsmani’ yang kemudian dinisbatkan kepada Amirul Mukminin Ustman Ra.

Para Ulama berbeda pendapat tentang penulisan ini, diantara mereka ada yang berpendapat bahwa tulisan tersebut bersifat taufiqi (ketetapan langsung dari Rasulullah). Mereka berlandaskan riwayat yang menyatakan bahwa Rasulullah menerangkan kepada salah satu Kuttab (juru tulis wahyu) yaitu Mu'awiyah tentang tatacara penulisan wahyu. Diantara ulama yang berpegang teguh pada pendapat ini adalah Ibnul al-Mubarak dalam kitabnya "al-Ibriz" yang menukil perkataan gurunya, Abdul 'Aziz al-Dibagh bahwa "tulisan yang terdapat pada Rasm 'Utsmani semuanya memiliki rahasia-rahasia dan tidak ada satupun sahabat yang memiliki andil. Seperti halnya diketahui bahwa Al-Quran adalah mu'jizat begitupula tulisannya”. Namun disisi lain, ada beberapa ulama yang mengatakan bahwa, Rasmul Ustmani bukanlah tauqifi, tapi hanyalah tatacara penulisan al-Quran saja. 


\section{ISI DAN PEMBAHASAN}

\section{A. Pengertian Rasm Al-Quran}

Arti rasm menurut bahasa adalah atsar (bekas). Lafal rasm sinonim (muradif) dengan lafal khat, kitabah, zubur, satr dan raqm. Rasm ada dua macam, yaitu qiyasi dan istilahi. Rasm qiyasi yang biasa disebut juga Rasm imla'i adalah penggambaran lafal yang menggunakan huruf hijaiyah, dengan tetap memperhatikan standarisasi ibtida' dan waqof padanya. Sedang Rasm istilahi yang bisa juga disebut Rasm Usmani adalah ejaan tulisan Zaid bin Tsabit dan kawan-kawan yang dipakai untuk menulis al-Masahif al-Usmaniyah. Malik Hammad, (:12)

Dalam kitab Manahil al-'Irfan Fi 'Ulum Al-Qur'an disebutkan bahwa yang dimaksud dengan Rasm Al-Qur'an atau al-Mushaf adalah:

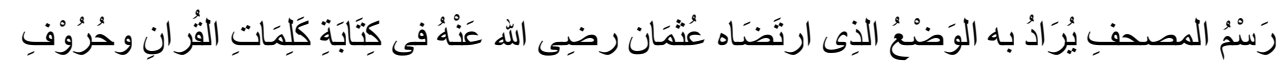

"Rasm mushaf yang dimaksud disini adalah kaidah yang disepakati oleh Utsman RA. dalam penulisan kalimat-kalimat Al-Qur'an dan hurufnya".

\section{B. Sejarah Perkembangan Rasm Al-Qur'an}

Pada mulanya mushaf para sahabat yang berbeda antara satu dengan yang lainnya mereka mencatat wahyu Al-Qur'an tanpa pola penulisan standar, karena umumnya dimaksutkan hanya untuk kebutuhan pribadi, tidak direncanakan akan diwariskan kepada generasi sesudahnya.

Di zaman Nabi saw, Al-Qur'an ditulis pada benda-benda sederhana, seprti kepingankepingan batu, tulang-tulang kulit unta dan pelepah kurma. Tulisan Al-Qur'an ini masih terpencar-pencar dan belum terhimpun dalam sebuah mushaf dan disimpan dirumah Nabi saw. Penulisan ini bertujuan untuk membantu memelihara keutuhan dan kemurnian Al-Qur'an. Di zaman Abu Bakar, Al-Qur'an yang terpancar-pancar itu di salin kedalam shuhuf (lembaranlembaran).

Penghimpunan Al-Qur'an ini dilakukan Abu Bakar setelah menerima usul dari Umar bin al-Khattab yang khawatir akan semakin hilangnya para penghafal Al-Qur'an sebagaimana yang terjadi pada perang yamamah yang menyebabkan gugurnya 70 orang penghafal Al-Qur'an. Karena itu, tujuan pokok dalam penyalinan Al-Qur'an di zaman Abu Bakar masih dalam rangka pemeliharaan agar jangan sampai ada yang terluput dari Al-Qur'an. Abdul Wahid, $(2002: 31)$ 
Di zaman khalifah Usman bin Affan, Al-Qur'an disalin lagi kedalam beberapa naskah. Untuk melakukan pekerjaan ini, Utsman membentuk tim 4 yang terdiri dari Zaid bin Tsabit, Abdullah Ibn Az-Zubair, Saad Ibn al-Ash, dan Abd al-Rahman Abd al_harits.

Dalam kerja penyalinan Al-Qur'an ini mereka mengikuti ketentuan-ketentuan yang disetujui oleh Khalifah Usman. Di antara ketentuan-ketentuan itu adalah bahwa mereka menyalin ayat berdasarkan riwayat mutawatir, mengabaikan ayat-ayat Mansukh dan tidak diyakini dibaca kembali dimasa hidup Nabi saw. Tulisannya secara maksimal maupun diakomodasi ira'at yang berbeda-beda, dan menghilangkan semua tulisan sahabat yang tidak termasuk ayat Al-Qur'an. Para penulis dan para sahabat setuju dengan tulisan yang mereka gunakan ini. Para ulama menyebut cara penulisannya ini sebagai rasm al-Mushaf. Karena cara penulisan disetujui oleh Usman sehingga sering pula dibangsakan oleh Usman. Sehingga mereka sebut rasm Usman atau rasm al-Usmani. Namun demikian pengertian rasm ini terbatas pada mushaf oleh tim 4 di zaman Usman dan tidak mencakup rasm Abu Bakar pada zaman Nabi saw. Bahkan,Khalifah Usman membakar salinan-salinan mushaf tim 4 karena kawatir akan beredarnya dan menimbulkan perselisihan dikalangan umat Islam. Hal ini nanti membuka peluang bagi ulama kemudian untuk berbeda pendapat tentang kewajiban mengikuti rasm Usmani. Abdul Wahid, (2002:31)

\section{Hukum Dan Kedudukan Serta Pendapat Ulama Tentang Rasm Al-Qur'an.}

Kedudukan rasm Usmani diperselisihkan para ulama, pola penulisan tersebut merupakan petunjuk Nabi atau hanya itjtihad kalangan sahabat. Adapun pendapat mereka sebagai berikut:

Kelompok pertama (Jumhur Ulama) berpendapat bahwa pola rasm Usmani bersifat tauqifi dengan alasan bahwa para penulis wahyu adalah sahat-sahabat yang ditunjuk dan dipercaya Nabi saw, dan para sahabat tidak mungkin melakukan kesepakatan (ijma') dalam hal-hal yang bertentangan dengan kehendak dan restu Nabi. Bentuk-bentuk inkonsentensi didalam penulisan Al-Qur'an tidak bisa dilihat hanya berdasarkan standar penulisan baku, tetapi dibalik itu ada rahasia yang belum dapat terungkap secara keseluruhan. Pola penulisan tersebut juga dipertahankan para sahabat dan tabi'in. Shihab, dkk(2001: 95).

Dengan demikian menurut pendapat ini hokum mengikuti rasn Usmani adalah Wajib, dengan alasan bahwa pola tersebut merupakan petunjuk Nabi (taufiqi). pola itu harus dipertahankan meskipun beberapa diantaranya menyalahi kaidah penulisan yang telah dibakukan. Bahkan imam Ahmad Ibn Hambal dan Imam Malik berpendapat bahwa haram hukumnya menulis Al-Qur'an menyalahi rasm Usmani. Bagaimanapun, pola tersebut sudah merupakan kesepakatan ulama mayoritas (Jumhur Ulama). 
Kelompok Kedua berpendapat, bahwa pola penulisan di dalam rasm Usmani tidak bersifat taufiqi, tetapi hanya bersifat ijtihad para sahabat. Tidak ditemukan riwayat Nabi mengenaiketentuan pola penulisan wahyu. Bahkan sebuah riwayat yang dikutip oleh rajab Farjani. Sesungguhnya Rasulullah SAW. Memerintahkan menulis Al-Qur'an, tetapi tidak memberikan petunjuk teknis penulisannya, dan tidak melarang menulisnya dengan pola-pola tertentu. Karena itu ada perbedaan model-model penulisan Al-Qur'an dalam mushaf-mushaf mereka. Ada yang menulis suatu lafaz Al-Qur'an sesuai dengan bunyi lafaz itu, ada yang menambah atau menguranginya, karena mereka tau itu hanya cara. Karena itu dibenarkan menulis mushaf dengan pola-pola penulisan masa lalu atau pola-pola baru. Rajab Farjani, (1978:166).

Lagi pula, seandainya itu petunjuk nabi, rasm itu akan disebut rasn Nabi, bukan rasn Usmani. Belum lagi kalau ummi diartikan sebagai buta huruf, yang berarti tidak petunjuk teknis dari Nabi. Tidak perna ditemukan suatu riwayat, baik dari Nabi maupun sahabat bahwa pola penulisan Al-Qur'an itu bersumber dari petunjuk Nabi.

Kelompok ini pula berpendapat bahwa tidak ada masalah juka Al-Qur'an ditulis dengan pola penulisan standar (rasm Imla'i). soal penulisan diserahkan kepada pembaca, kalau pembaca merasa lebih muda dengan rasm imla'I, ia dapat menulisnya denga pola tersebut, karena pola penulisan itu symbol pembacaan, dan tidak mempengaruhi makna Al- Al-Qur'an. Shihab, (2001:89).

Sehubungan ini, mereka menyatakan sebagai berikut: sesungguhnya bentuk dan model penulisan itu tidak lain hanyalah merupakan tanda atau symbol. Karena itu segala bentuk serta model tulisan Al-Qur'an yang menunjukan arah bacaan yang benar, dapat dibenarkan. Sedangkan rasm Usmani yang menyalahi rasm Imla'I sebagaimana kita kenal, menyulitkan banyak orang serta bisa mengakibatkan berat dan kacau bagi pembaca. Kelompok ketiga Mengatakan, bahwa penulisan Al-Qur'an dengan rasm Imla'I dapat dibenarkan, tetapi kusus bagi orang awam. Bagi para ulama atau yang memahami rasm Usmani, tetap wajib mempertahankan keaslian rasm tersebut. Pendapat ini diperkuat al-Zarqani dengan mengatakan bahwa rasm Imla'i diperlukan untuk menghindarkan umat dari kesalahan membaca Al-Qur'an, sedang rasm Usmani diperlukan untuk memelihara keaslihan msuhaf Al-Qur'an. Syihab,(2001:89)

Tampaknya pendapat yang ketiga ini berupaya mengkompromikan antara dua pendapat terdahulu yang bertentangan. Di satu pihak mereka ingin melestarikan rasm Usmani, sementara dipihak yang lain mereka menghendaki dilakukannya penulisan Al-Qur'an dengan rasm Imla'I 
untuk memberikan kemudahan bagi kaum muslimin yang kemungkinan mendapat kesulitan membaca Al-Qur'an dengan rasm Usmani. Dan pendapat ketiga ini lebih moderat dan lebih sesuai dengan kondisi umat. Memang tidak tidak ditemukan nashditemukan nash yang jelas diwajibkan penulisan Al-Qur'an dengan rasm Usmani. Namun demikian, kesepakatan para penulis Al-Qur'an dengan rasm usmani harus di indahkan dalam pengertian menjadikannya sebagia rujuan yang keberadaannya tidak bole hilang dari masyarakat islam. Sementara jumlah umat islam dewasa ini cukup besar dan tidak menguasai rasm Usmani. Bahkan, tidak sedikit jumlah umat islam yang tidak mampu membaca aksara arab. Mereka membutuhkan tulisan lain untuk membantu mereka agar membaca ayat-ayat Al-Qur'an, seperti tulisan latin. Namun demikian, Al-Qur'an dengan rasm Usmani harus dipelihara sebagai sandar rujukan ketika dibutuhkan. Demikian juga tulisan ayat-ayat Al-Qur'an dalam karya imiah, rasm Usmani mutlak diharuskan karena statusnya sudah masuk dalam kategori rujukan dan penulisannya tidak mempunyai alasan untuk mengabaikannya.

Dari ketiga pendapat diatas penulis lebih cenderung menyatakan, bahwa untuk penulisan Al-Qur'an secara utuh sebagai kitab suci umat Islam, semestinya mengikuti dan berpedoman kepada rasm usmani, hal ini mengingat pertimbangan-pertimbangan sebagai berikut:

1. Agar umat Islam diseluruh dunia memiliki kitab suci yang seragam dalam pola penulisannya, sesuai dengan pedoman aslinya.

2. Pola penulisan Al-Qur'an dengan rasm Usmani, kalaupun tidak bersifat taifiqi minimal telah merupakan ijma' atau kesepakatan para sahabat Nabi. Ijla' sahabat memiliki kekuatan hokum tersebut yang wajib diikuti, termasuk dalam penulisan Al-Qur'an dengan rasm Usmani (bila dimaksutkan sebagai kitab suci secara utuh).

3. Pola penulisan Al-Qur'an berdasarkan rasm Usmani boleh dikatakansebagian besar sesuaidengan kaidah-kaidah rasm Imla'I dan hanya sebagian kecil saja yang menyalahi atau berbeda dengan rasm Imla'i.

\section{Kaidah-Kaidah Rasm Al-Quran}

Rasm Usmani disebut juga Rasmul Al-Qur'an atau Rasm Usman adalah tata cara menuliskan Al-Qur'an yang ditetapkan pada masa khlalifah Utsman bin Affan. Istilah rasmul Al-Qur'an diartikan sebagai pola penulisan Al-Qur'an yang digunakan Ustman bin Affan dan sahabat-sahabatnya ketika menulis dan membukukan Al-Qur'an. Yaitu mushaf yang ditulis oleh panitia empat yang terdiri dari, Mus bin zubair, Said bin Al-Ash, dan Abdurrahman bin Al-harits.

Mushaf Usman ditulis dengan kaidah tertentu. 
Kaidah ini teringkas dalam enam kaidah;

1. Penghapusan (al-Hadzf), seperti penghapusan huruf-huruf sebagai berikut:

a. Huruf alif yang terdapat pada ya' nida' (ya' seruan) sebagaimana yang tercantum dalam bunyi ayat يأْيها الناس, huruf alif yang terdapat pada ha at-tanbih(peringatan). sebagaimana tercantum dalam bunyi ayat هانتم هؤلاء, huruf alif yang terdapat apabila diikuti oleh suatu dhamir, seperti واتينه dan huruf alifterdapat setiap bentuk jama' shahih, baik untuk jama' mudzakkar atau jama' muannats seperti المسلمات serta huruf alif yang terdapat pada setiap bentuk jama'yang menyerupai wazan mafaa'ilu dan yang serupa dengannya, seperti مساجد.

b. Huruf ya yang terdapat pada setiap lafazh al-manqush yang bertanwin, baik dalam keadaan rafa' maupun jarr, seperti ungkapan غيرباغ ولاعاد dan huruf yadalam ungkapan seruan, seperti ungkapan: يعباد فاتِّون kecuali dalam ungkapan قل ياعبادي الذعين اسرفوا.

c. Huruf wawu apabila terjadi bersamaan dengan huruf wawu yang lain, seperti lafazh لايستون.

2. Penambahan (az-ziyadah), sebagaimana penambahan huruf-huruf berikut ini:

3. Penambahan huruf alif di akhir isim yang dijama'kan atau dalam hukum yang serupa dengannya, seperti dalam lafadz الظنونا dan huruf alif yang terletak antara huruf jim dan huruf ya dalam lafadz وجئ dalam surah az-Zumar, sedangkan di dalam suratnya tertulis با ييكم لمفنون Penambahan huruf ya, sebagaimana lafadz و وجايء

a.Penambahan huruf wawu, sebagaimana lafadz اولئك

Aturan hamzah yang terdiri atas beberapa macam, yaitu berikut ini:

1) Al-Hamzah al-Sakinah yang aslinya ditulis di atas huruf yang sesuai dengan harakat sebelumnya, baik di awal, tengah, maupun akhir, قراً kecuali dalam katakata tertentu, seperti فادار وثم maka kedua kata tersebut hurufnya dihilangkan dan hamzah ditulis menyendiri.

2) Al-Hamzah al-Mutaharrikah apabila berada di awal kata atau digabungkan dengan huruf tambahan, hamzah tersebut ditulis dengan alif secara pasti (mutlak, baik dalam keadaan fatah, dammah maupun kasrah, seperti kata اولوا. اذا, أيوب kecuali di tempat-tempat tertentu seperti قل أينكم لنكفرون di dalam surah Fushshilat.

4. Ibdal (mengganti).

a. Setiap alif yang merupakan refleksi (munqalabah) huruf al-ya'u ditulis dengan huruf al-ya', seperti kata يثوفيكم dalam isim atau fi'il yang bersambung 
ياحسرثي, يأسفي علي يوسف dengan dhamir atau tidak, yang tetap sukun atau tidak, seperti . هداني, kecuali seperti kata.

b. Nun taukid khafif ditulis dengan huruf alif, begitupula nun dalam kata (اذا) sedangkan ungkapa وكأين من نبي, maka ditulis dengan nun.

c. Ha' at-Ta'nis ditulis dengan huruf ta yang berbeda dengan huruf aslinya di beberapa tempat di dalam Al-Qur'an, seperti kata رحمة dalam surah al-Baqarah, Maidah, dan lain-lain.

5. Aturan pemisahan (al-fashl) dan penyambungan (al-washl). Di dalam tulisan, Aturan alBadal (penggantian) yang terdiri atas beberapa macam aturan, yaitu:

a. Gambar alif ditulis dengan wawu untuk menyatakan keagungan (al-tafkhim), terkadang sebagian lafadz ditulis secara bersambung dan terkadang ditulis secara terpisah, dan sebagian lagi ditulis dalam satu keadaan tertentu.

b. Penyambungan kata lengan fathah hamzahnya disambungkan (washl) dengan $\gamma$, bila jatuh sesudahnya seperti lafadz ألاثقولو dalam surah al-A'raf. Dari kaidah ini dikecualikan sepuluh tempat, antara lain kata أن لاتعبدوا dalam surah Huud dan surah Yasin, kata وان لاثعلو اعلي اله dalam surah al-Dukhan.

c. Penyambungan kata مما kecuali di dalam ungkapan من ماملكث أيمانكم dalam surah alNisa dan al-Ruum, ungkapan من مارزقناكم dalam surah al-Munafiqun, penyambungan kata sمن secara mutlak.

d. Penyambungan kata عما عن مانهو اعنه kecuali di dalam.

e. Penyambungan kata عمن kecuali di dalam firman-Nya ويصرفه عن من يشاء. dalam surah an-Nur, dan firman-Nya عن من تولي dalam surah an-Najm.

f. Penyambungan kata secuali dalam firman-Nya ملما مل ماردو اللي الفتنة dan firman-Nya من .

g. Penyambungan kata أمن, kecuali dalam firman-Nya أمن يكون عليهم وكيلا dalam surah anNisa, penyambungan kata اما dengan harakat kasrah pada huruf hamzahdan syiddah, kecuali dalam ungkapan ومانرينأ dalam surah ar-Ra'du.

h. Penyambungan kata أنما dengan harakat fatah pada huruf hamzah secara mutlak. Dan lafaz-lafaz lainnya yang sewaktu-waktu ditulis secara bersambung dan sewaktusewaktu terpisah, seperti kata أنما أن لم dengan harakat dan kasrah.

i. Lafadz-lafadz yang memiliki dua bacaan maka ditulis menurut salah satunya, seperti lafaz dan yang sejenisnya. Semuanya dibaca dengan menetapkan alif, atau 
dengan menghilangkannya. Demikian pula, kata-kata yang ditulis dengan ta' maftuhah, yaitu ثمرة من أكمامها dalam surah Fushshilat. Muhammad Hasbi(2009:149)

\section{E. Karakteristik Rasm Usmani}

Karakteristik adalah ciri atau identitas khas yang membedakan identitas satu dengan yang lain. Dan Rasm Usmani mendapatkan kedudukan yang tinggi, disamping karena khalifah telah menyetujuinya dan menetapkan pelaksanaannya. Bahkan ada yang menetapkan bahwa Rasm Ustmani adalah RASM TAUQIFI yang cara penulisannya ditentukan oleh Nabi sendiri.

Selain keindahan tulisan Rasm Usmani,penulisan Rasm Usmani ini juga memenuhi kaidah Sab'atu Ahruf. Dan mereka dapat mengenali dengan baik huruf-huruf dan kata-kata, baik bentuk, harakat, kondisi-kondisi huruf dengan memperhatikan indikasi setiap kalimat yang ada sehingga mereka dapat membacanya dengan baik dan benar. Mahdi Saif,( 1380: 14-15). Sebagaimana pada sebagian bahasa seperti bahasa Persia yang pada mulanya disertai dengan tanda baca, namun setelah itu, ditulis dan dibaca tanpa tanda baca.Jenis tulisan disebabkan oleh masalah-masalah yang disebutkan di atas dan seiring dengan kemajuan Islam di kalangan kaum-kaum lainnya, memerlukan perbaikan yang pada akhirnya setelah berlalunya beberapa dekade terjadi perubahan serius pada tulisan-tulisan berbahasa Arab sehingga kekurangankekurangan ini dapat teratasi.

Dalam sebuah pandangan global, beberapa Karakteristik Rasm Usmani dapat dijelaskan sebagai berikut:

1. Tulisan-tulisan pada masa itu, tidak memiliki titik, baris dan tanda baca. Tipologi tulisan Arab seperti ini pada masa itu dapat kita saksikan pada manuskrip-manuskrip kuno berbahasa Arab pada hari ini.

2. Kebanyakan huruf, khususnya huruf-huruf alif belum lagi ditulis; seperti kata-kata seperti al-rahmân(الرحمان), al-‘âlamîn (العالمين), mâlik (صالك), shirât(صر اطل) yang ditulis dalam bentuk “al-rahman (الرحمن),al-'alamîn (العلمين), malik (ملى), shirat (صرطن)."

3. Sebagian huruf ditulis sama dengan bentuk huruf lainnya; seperti alif pada kata-kata “shalat (صلاة), zakat (زلاة), hayat (حياة),..." ditulis dengan menyertakan huruf wâw; seperti shalat (صلوة), zakat (حيوة) atau alif pada kata-kata

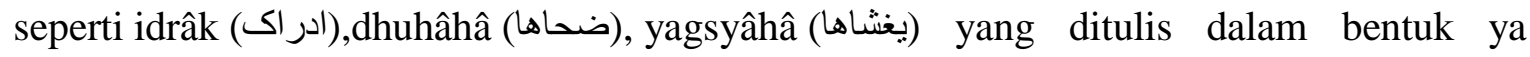
(ادريك), didrak (ضحديها), dhuhahâ (يغشيها).

4. Sebagian huruf dalam bentuk tambahan yang ditulis pada pelafalan; seperti pada kata-kata, “yad'un (يدعون),yatlu (يتلو), miat (مئة), ji (جى؟), lisyai (لنىى)... Yang ditulis dalam bentuk 
huruf alif tambahan seperti “yad'un (يدعون), yatlû (يتلون), miata (مائة), jaa (جاىء), lisyai

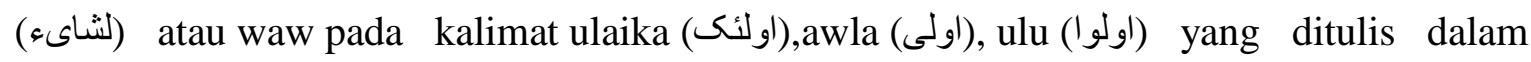
bentuk tambahan pada pelafalan. Abu Zitihar,( t.th: 6-7)

\section{F. Hukum Menulis Al-Quran Sesuai Dengan Rasm Usmani}

Sebagian ulama berpendapat bahwa keharusan kita mengikuti rasm Utsmani adalah untuk memelihara persatuan, supaya tetap berpegang satu syiar dan satu istilah. Karena pembuat keputusan adalah Utsman dan pelaksananya Zaid Ibn Tsabit, seorang penulis wahyu dan kepercayaan Rasul.

Ahmad Ibn Hambal berkata :

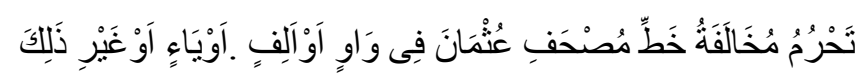

“Haram menyalahi tulisan Mus'haf Utsman, baik pada waw, alif, ya' atau yang lain"

Imam Malik berpendapat mengenai orang yang menulis Al-Qur'an dengan Qaidah Hijaiyyah (Qaidah Imla') :

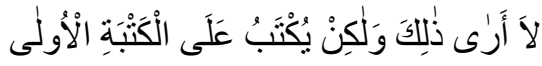

"Saya tidak berpendapat demikian, akan tetapi hendaklah ditulis menurut tulisan pertama"

kewajiban mengikuti pola penulisan Al Al-Qur'an versi Mushaf 'Utsmani diperselisihkan para ulama. Ada yang mengatakan wajib, dengan alasan bahwa pola tersebut merupakan petunjuk Nabi (tauqifi). Pola itu harus dipertahankan walaupun beberapa di antaranya menyalahi kaidah penulisan yang telah dibakukan. Bahkan Imam Ahmad ibn Hanbal dan Imam Malik berpendapat haram hukumnya menulis Al Al-Qur'an menyalahi rasm 'Utsmani. Bagaimanpun, pola tersebut sudah merupakan kesepakatan ulama mayoritas (jumhur ulama).

Dengan demikian, Ulama yang tidak mengakui rasm 'Utsmani sebagai rasm tauqifi, berpendapat bahwa tidak ada masalah jika Al Al-Qur'an ditulis dengan pola penulisan standar (rasm imla'i). Soal pola penulisan diserahkan kepada pembaca. Kalau pembaca lebih mudah dengan rasm imla'i, ia dapat menulisnya dengan pola tersebut, karena pola penulisan itu hanya simbol pembacaan, dan tidak mempengaruhi makna Al Al-Qur'an.

Al-Bukhari meriwayatkan hadits dari Abdullah bin Abbas, beliau berkata bahwa Rasulullah bersabda:

$$
\text { قر أنى جبريل على حرف فراجعته فلم أزل أستزيد ويزيدني حتى انتهى إلى سبعة أحرف }
$$

Artinya:"Jibril membacakan kepadaku satu huruf (bacaan) Al-Qur'an lalu saya mengikutinya. Tidak henti-hentinya saya memintanya mengulangi. Dan dia mengulanginya hingga sampai tujuh (macam) bacaan". (HR. Bukhari). 
Hadits ini adalah dalil bahwa Al-Qur'an memang diturunkan dengan tujuh macam qira'ah. Ketujuhmacam qiraah tadi adalah shahih berdasar pengajaran Jibril kepada Rasulullah dan ketujuh macam qiraah tadi juga disampaikan semuanya kepada sahabat. Sebagaimana dijelaskan di atas mengikuti rasm utsmani adalah wajib. Hukum wajib ini akan bertentangan dengan status shahih dari qiraah yang lain dan bisa mengharamkan qiraah sahih dan mutawatir lain yang tidak sesuai dengan rasm utsmani. Syeikh Muhammad Ali Ad Dlibagh mengatakan bahwa, rasm utsmani adalah salah satu rukun dari rukun-rukun ketujuh qira'ah Al-Qur'an, maka setiap qira'ah sama sekali tidak bertentangan dengan rasm utsmani. Beliau menambahkan bahwa ketika seseorang menulis Al-Qur'an yang di dalamnya ada qiraah yang berbeda dan harus menggunakan tulisan yang berbeda pula, maka yang harus dilakukan menulisnya sesuai dengan rasm utsmani lalu memberinya harakat atau tanda-tanda lain, sehingga ia tidak dikatakan menyalahi mushaf utsmani. Sebab yang diharuskan mengikuti rasm utsmani ialah hanya bentuk penulisan.

\section{PENUTUP}

\section{Kesimpulan}

Rasm Usmani disebut juga Rasmul Al-Qur'an atau Rasm Utsman adalah tata cara menuliskan Al-Qur'an yang ditetapkan pada masa khlalifah Utsman bin Affan. Istilah rasmul Al-Qur'an diartikan sebagai pola penulisan Al-Qur'an yang digunakan Ustman bin Affan dan sahabatsahabatnya ketika menulis dan membukukan Al-Qur'an.

Tentang hukum menulis ayat-ayat Al-Qur'an menurut rasm Al-Qur'an para ulama berbeda pendapat ada yang berpendapat bahwa itu taufiqi dan ada pula yang berpendapat bahwa itu adalah ijtihadi.

Ada beberapa kaidah dalam menulis rasm usmani, Kaidah ini teringkas dalam enam kaidah;

1. Penghapusan (al-Hadzf)

2. Penambahan (az-ziyadah)

3. Aturan hamzah

4. Ibdal (mengganti)

5. Aturan pemisahan (al-fashl) dan penyambungan (al-washl).

6. Kalimat yang mengandung 2(dua) bacaan dan ditulis dengn salah satunya saja.

Hukum menulis AlAl-Qur'an dengan Rasm Usmani adalah wajib karena, Kaidah penulisan Rasm Usmani telah di sepakati para Jumhurul Ulama'. 


\section{DAFTAR RUJUKAN}

Abdul, Wahid, Ramli. Ulum Al-Qur'an.Edisi Revisi, Jakarta: P.T Grafindo Persada, Cet, IV 2002.

AF, Hasanuddin. Anatomi Al-Qur'an perbedaan Qira'at dan pengaruhnya terhadap istinbat hukum dalam Al-Qur'an.CeI,Jakarta:P.T Raja Grafindi Persada. 1995.

Ahmad Warsono. Munawir Kamus al-Munawir, Yogyakarta: t.tp. 1954

Al-Zarqazi, Muhammad Ibnu Abdillah, al-Burhan fi Ulum Al-Qur'an. Jilid I, Cairo:Maktabah: Isa al-Babi al-Haklabi wal syirkah, 1997.

Ash-Siddieqy, Muhammad Hasbi. Ilmu-Ilmu Al-Quran. Semarang: PT Pustaka Rizki Putra, Cet, III 2009.

Bahri, saiful. Pedoman Ilmu Tajwid. Blitar : Mubarakatan Thoyibah, 2011

Fajrani, Muhammad Rajab. Kaifa Nata'abbad Ma'a al-Mushaf,. Cairo: Daar al-I'tisham. T.tp 1978

Khalil, Moenawar. Al'Al-Qur'an dari masa ke masa.Cet VI, Solo: CV Ramadani, 1985.

Shihab, M. Qurays,dkk. Sejarah dan ulum Al-Qur'an. Cet III, Jakarta :pusat Firdaus,2001

(Times New Roman 12, Reguler, spasi 1, spacing before 6 pt, after 6 pt). 